*Especialista em Direito do Estado com área de concentração em Direito Tributário, Universidade Estadual de Londrina. Advogada em São José do Rio Preto - SP.

** Doutor e Mestre em Direito do Estado pela Universidade Federal do Paraná. Especialista em Direito Tributário pelo Instituto Brasileiro de Estudos Tributários. Professor da graduação da PUC-PR campus Londrina e das Faculdades Londrina. Professor da PósGraduação "lato sensu" em Direito em diversas instituições. Advogado. Membro do Instituto de Direito Tributário de Londrina - IDTL.

\section{Instrumentos Tributários No Estatuto Da Cidade em Prol da Função Social E Do Meio Ambiente}

\author{
Tax Instruments In City Status In Support Of Social \\ Role And The ENVIRONMENT
}

\section{Leticia Emanueli Cruz Silva* Carlos Renato da Cunha**}

Como citar: SILVA, Leticia Emanueli Cruz; CUNHA Carlos Renato da. Instrumentos tributários no Estatuto da Cidade em prol da função social e do meio ambiente. Revista do Instituto de Direito Constitucional e Cidadania - IDCC, Londrina, v. 5, n. 1, p 10-30, jan/jul, 2020. ISSN: 2596-0075. https://doi.org/10.48159/revistadoidcc.v5n1.silva.cunha

Resumo: Pretende-se com este trabalho analisar a função social da propriedade, inserindo-a dentro do contexto urbano e a necessidade de um posicionamento ativo do Estado na consecução direito constitucional ao meio ambiente ecologicamente equilibrado. Desta feita, avaliaram-se as ferramentas tributárias previstas expressamente no Estatuto da Cidade como medidas a serem incentivadas, haja vista a repercussão destas sobre as ações humanas e conseguinte organização espacial.

Palavras-chave: Função Social da Propriedade. Instrumentos Tributários. Meio Ambiente Urbano.

\begin{abstract}
The aim of this work to analyze the social function of property, including it within the urban context and the need for an active position of the State in achieving constitutional right to an ecologically balanced environment. That way, the tax tools provided expressly evaluated in the City Statute as measures to be encouraged, given the impact of these on human actions and therefore spatial organization.
\end{abstract}


Keywords: Social Function of Property. Tax instruments. Urban Environment. 


\section{INTRODUÇÃO}

A mentalidade moderna requisitou dos Estados atitudes mais positivas em prol dos direitos de terceira geração, égide sobre a qual se promulgou a Constituição de 1988, que, como fruto desse período histórico, positivou determinados direitos difusos, como a função social da propriedade e o meio ambiente ecologicamente equilibrado.

O direito a propriedade, portanto, passa a ser observado sob um novo prisma, não podendo mais se restringir ao campo daquele que o detém, mas sim sobre um óptico macro abordando todo o ambiente no qual se insere.

Meio ambiente este que deve ser interpretado no seu sentido mais amplo, de maneira que seja capaz de segmentar-se em diferentes espécies, mas sobre as quais recai o mesmo agasalho jurídico.

Nesta seara nasce a preocupação acerca do meio ambiente urbano e o dever dos entes políticos de promover uma política pública urbana adequada aos anseios sociais e capaz de organizar a ocupação das cidades, sem olvidar ainda do direito de propriedade.

Assim nasceu o Estatuto da Cidade como lei nacional norteadora da ordem pública e interesse social no âmbito urbano. Norma que trouxe expressamente alguns dos instrumentos que o Estado pode usar no logro de um meio ambiente urbano equilibrado.

Dentre essas ferramentas destacamos os institutos tributários do Imposto Predial e Territorial Urbano e das Contribuições de Melhoria como medidas pré existentes no ordenamento e confirmadas pelo Estatuto da Cidade como meios eficazes de implementação da política urbana por parte do Poder Público.

\section{FUNÇÃO SOCIAL DA PROPRIEDADE}

O conceito de propriedade evoluiu junto com a sociedade e moldou-se de acordo com as necessidades dessa. Assim, no decorrer do tempo o direito de propriedade pode ser traduzido de diferentes formas, desde um poder absoluto de alguém, que a dispunha em sua plenitude e de maneira exclusiva, até a contemporaneidade, em que cada vez mais o conceito voltar-se ao interesse coletivo e ao seu papel social.

Em um breve resumo Carlos Roberto Gonçalves delineia a trajetória da ideia de propriedade no tempo.

No direito romano, a propriedade tinha caráter individualista. Na Idade Média, passou por uma fase peculiar, com a dualidade de sujeitos (o dono e o que explorava economicamente o imóvel, pagando ao primeiro pelo o seu uso). Havia todo um sistema hereditário para garantir que o domínio pertencesse numa dada família de tal forma que esta não perdesse o seu poder no contexto do sistema politico.

Após a Revolução Francesa, a propriedade assumiu feição marcadamente individualista. No século passado, no entanto, foi acentuado o seu caráter social, 
contribuindo para essa situação as encíclicas Rerum Novarum, do Papa Leão XIII, e Quadragésimo Ano, de Pio XI. O sopro da socialização acabou, com efeito, empregnando o século XX, influenciando a concepção da propriedade e o direito das coisas. (GONÇALVES, 2012 p. 249)

Isto posto, atualmente vivenciamos o direito da propriedade de maneira quase transcendental, em outras palavras, hoje o exercício desse direito não se restringe a conveniência daquele que o detém, mas sim a toda a comunidade que o permeia.

Nas palavras de Gilmar Mendes “essa evolução fez com que o conceito constitucional de direito de propriedade se desvinculasse, pouco a pouco, do conteúdo eminentemente civilístico de que era adotado". (BRANCO, et al., 2012 p. 431)

Não obstante a relativização do caráter absolutista da propriedade, esta nova acepção não desagua na extinção desse direito ou mesmo no fim do seu caráter privativo, mas tão somente traz um novo delineado ao tema.

O direito de propriedade, então, segue como um direito fundamental e como tal vê-se fulcrado no texto constitucional de maneira expressa no art. $5^{\circ}$, XXII: "É garantido o direito de propriedade". Desta feita, como leciona José dos Santos Carvalho Filho “o mandamento indica que o legislador não pode erradicar esse direito do ordenamento jurídico positivo. Pode, sim, definir-lhe os contornos e fixar-lhe limitações, mas nunca deixará o direito de figurar como objeto da tutela jurídica”. (CARVALHO FILHO, 2012 p. 768)

E dentre os contornos, um foi especificamente já traçado pelo legislador constituinte, garantindo assim sua observância por todo o plano infraconstitucional. Trata-se da ideia de função social, que, de tamanha importância mereceu previsão expressa na Constituição de 1988, assim como o próprio direito ao qual se filia: art. $5^{\circ}$ XXIII "a propriedade atenderá a sua função social".

É a chamada constitucionalização do direito privado, que se concretiza por meio de princípios que possibilitam o exercício do direito civil a luz dos ditames constitucionais, elevando os valores existenciais em detrimentos dos direitos patrimoniais. A dignidade da pessoa humana passou a ser o centro onde orbitam as normas jurídicas.

É o caso do princípio da função social da propriedade, que foi introduzido dentro do mais alto patamar do ordenamento jurídico como um conceito aberto capaz de traduzir os dinamismos necessários a modernização do conceito de propriedade junto à sociedade, sem, todavia, extirpar as garantias já alcançadas.

A ideia de função social, portanto, se agrega a própria ideia de propriedade, e assim, como bem recorda José Afonso da Silva, "não se confunde com os sistemas de limitação da propriedade. Estes dizem respeito ao exercício do direito ao proprietário; aquela à estrutura do direito mesmo, à propriedade”. (SILVA, 1999 p. 284)

Impõem-se, deste modo, a análise do conceito de propriedade e sua função social diante do ponto de vista de cada momento histórico.

Arrematando o explanado, o pensamento de Gilmar Mendes, in verbis: 
Não existe, todavia, um conceito constitucional fixo, estático, de propriedade, afigurando-se, fundamentalmente, legitimas não só as novas definições de contudo como a fixação de limites destinados a garantir a sua função social. É que embora não aberto, o conceito constitucional de propriedade há de ser necessariamente dinâmico.

Nesse passo, deve-se reconhecer que a garantia constitucional da propriedade está submetida a um intenso processo de relativização, sendo interpretada, fundamentalmente, de acordo com parâmetros fixados pela legislação ordinária. As disposições legais relativas ao conteúdo têm, portanto, inconfundível caráter constitutivo. Isso não significa, porém, que o legislador possa afastar os limites constitucionalmente estabelecidos. A definição desse conteúdo pelo legislador há de preservar o direito de propriedade enquanto garantia institucional. Ademais, as limitações impostas ou as novas conformações emprestadas ao direito de propriedade hão de observar especialmente o principio da proporcionalidade, que exige que as restrições legais sejam adequadas, necessárias e proporcionais. (BRANCO, et al., 2012 p. 446)

Conclui-se, portanto, que, em que pese à existência do princípio da função social, esse não é capaz de anular o núcleo essencial do conceito de direito de propriedade, qual seja, a utilidade privada e nos poderes de usar, gozar e dispor.

Nesse sentido, o supracitado autor complementa afirmando que "a vinculação social da propriedade, que legitima a imposição de restrições, não pode ir ao ponto de coloca-la, única e exclusivamente, a serviço do Estado ou da comunidade." (BRANCO, et al., 2012 p. 477)

A propriedade, deste modo, perde seu caráter exclusivo sobre qualquer vertente, ou seja, não pode ser colocada a disposição única da vontade do proprietário, mas também não há uma socialização do bem. Em verdade, deve-se ter em mente ambos os conceitos coexistindo em simbiose.

O ordenamento visou com a introdução desta ideia a conciliação entre os interesses individuais e coletivos "e somente quando há o conflito é que o Estado dá primazia a estes últimos. A função social pretende erradicar algumas deformidades existentes na sociedade, nas quais o interesse egoístico do individuo põe em risco os interesses coletivos", como bem lembra o doutrinador José dos Santos Carvalho Filho. (CARVALHO FILHO, 2012 p. 815)

Em suma, o direito de propriedade é um direito, por definição, protetor do interesse individual. Esse ideal privatista permanece, ainda que, quando em conflito com interesses coletivos devam prevalecer os segundos por força da função social.

Conquanto seja evidente que a noção de função social trata-se um conceito jurídico aberto, a Constituição nos oferece certos parâmetros objetivos a fim de melhor compreender o instituto. Para tanto, trouxe a baila dois prismas: a função social da propriedade urbana e da propriedade rural.

Para Flávio Tartuce, para quem se deve compreender a função social da propriedade como uma dupla intervenção: limitadora e impulsionadora, pela literalidade do Texto Maior, diferentemente do concernente a propriedade rural, a função social urbana não traz critérios claros 
e definidos, sendo por vezes necessária a aplicação dos parâmetros dispostos acerca da propriedade rural. (TARTUCE, 2014 p. 990)

Tal reflexão decorre da menção constitucional feita no Art. 182, § 2 ${ }^{\circ}$, in verbis, "A propriedade urbana cumpre sua função social quando atende às exigências fundamentais de ordenação da cidade expressas no plano diretor”.

Deste modo, o citado autor traça o aproveitamento racional e adequado da propriedade, a utilização adequada dos recursos naturais disponíveis e preservação do meio ambiente, observância das disposições que regulam as relações de trabalho e, por fim, a exploração que favoreça o bemestar dos proprietários e dos trabalhadores, como características definidoras do cumprimento da função social para qualquer propriedade. (TARTUCE, 2014 p. 990)

No entanto, apesar da coincidência nos parâmetros distintivos da função social nos diferentes tipos de propriedade, é hialino que cada uma delas possui caracteres singulares que resultam em medidas sancionatórias distintas, no objetivo de melhor adequá-la a sua realidade. Prova disso é a contraposição entre os artigos 182 , $§ 4^{1}$ e $184^{2}$ da Carta Magna.

Em resumo, a doutrinadora Maria Sylvia Zanella di Pietro concluiu que a aplicação da função social no âmbito urbano visa, especialmente, "obrigar o proprietário de terreno não construído a nele edificar ou proceder o parcelamento." (DI PIETRO, 2012)

Desta forma, a propriedade urbana, objeto do presente trabalho, cumpre sua função social quando além dos requisitos já debatidos, o faz em adequação as diretrizes do Plano Diretor, instrumento de politica urbana municipal que visa a organização da cidade.

De modo detido Cristiano Chaves aduz que:

(...) a diretriz a ser seguida pelo plano diretor é impedir a retenção especulativa e inadequada utilização do imóvel que acabem por interferir nos projetos de desenvolvimento urbano. A propriedade urbana que não atende a sua função social é aquela que frustra três requisitos alternativos: a) não estar edificada; b) estar subutilizada; c) não estar sendo utilizada. (FARIAS, et al., 2012 p. 325)

O Plano Diretor, dessa forma, dá objetividade à função social da propriedade na tentativa de tornar efetiva sua atuação e exigência.

Todavia, não é a única norma com esta finalidade. Embora seja evidente o valor desta lei, afinal, detém expressa previsão na Constituição, o nosso ordenamento conta também com outras normas urbanísticas de igual relevância.

\footnotetext{
1 Art. $182 \S 4^{\circ}$ É facultado ao Poder Público municipal, mediante lei específica para área incluída no plano diretor, exigir, nos termos da lei federal, do proprietário do solo urbano não edificado, subutilizado ou não utilizado, que promova seu adequado aproveitamento, sob pena, sucessivamente, de:

I - parcelamento ou edificação compulsórios;

II - imposto sobre a propriedade predial e territorial urbana progressivo no tempo;

III - desapropriação com pagamento mediante títulos da dívida pública de emissão previamente aprovada pelo Senado Federal, com prazo de resgate de até dez anos, em parcelas anuais, iguais e sucessivas, assegurados o valor real da indenização e os juros legais.

2 Art. 184. Compete à União desapropriar por interesse social, para fins de reforma agrária, o imóvel rural que não esteja cumprindo sua função social, mediante prévia e justa indenização em títulos da dívida agrária, com cláusula de preservação do valor real, resgatáveis no prazo de até vinte anos, a partir do segundo ano de sua emissão, e cuja utilização será definida em lei.
} 
É o caso do Estatuto da Cidade, Lei $n^{\circ} 10.257 / 01$, que estabelece diretrizes gerais para a politica urbana e deixa claro que a "finalidade social é tanto dirigida ao poder público como ao proprietário, pois seria inócuo se exigir um comprometimento isolado do particular se não houver toda uma organização da municipalidade no sentido de fazer as cidades um núcleo de solidariedade e amortecimento das desigualdades sociais". (FARIAS, et al., 2012 p. 325)

Assim sendo, o Estado deve se valer dessas ferramentas urbanísticas como um meio de disciplinar a ocupação do solo, redirecionando os recursos de maneira mais justa e garantindo um desenvolvimento urbano sustentável.

A propriedade é um direito individual, mas deve ser observada sob a ótica coletiva, por meio da qual sua função social torna-se um dever. E neste diapasão é que o Estado deve atuar, certificando-se de que a urbe se desenvolva tendo como centro o homem e não a propriedade, nos moldes do que preluz a Constituição Cidadã.

\section{EXTRAFISCALIDADE TRIBUTÁRIA}

\subsection{FunÇão do Tributo}

Todo arcabouço legal está direcionado a promover a eficiência do Estado Democrático de direito, ou seja, mirando o desenvolvimento social e econômico da nação.

Neste contexto, o tributo também é auferido como uma arma estatal não apenas provedora de fundos, mas também reguladora das atividades humanas, seja pela concessão de isenções, pela previsão constitucional de imunidades ou por uma grande carga tributária.

Para Cláudia de Rezende Machado de Araújo “o exercício do poder de tributar é, sem dúvida alguma, político, estando, portanto, sujeito mais a fatores políticos que econômicos. É uma questão de opção política por determinada técnica de tributação.” (ARAÚJO, 1996 p. 331)

Falamos então em política fiscal exercida por quem detém o poder soberano, através da qual, além de arrecadarem-se receitas para a manutenção da máquina estatal, determinados comportamentos são incentivados ou coibidos.

Os tributos são constituídos por um aparato legal extenso, que não só traz garantias ao contribuinte, como a possibilita ao Estado, por meio de seus representantes, a utilização desse arcabouço de maneira transcendente a arrecadatória.

Emergem, portanto, além da função fiscal, a extrafiscalidade como outro meio de intervenção estatal e promulgação dos pilares constitucionais e a parafiscalidade, que, embora mais próxima da capacidade tributária, também apresenta reflexos na acepção habitual da sociedade acerca da finalidade tributária. 
Segundo Aliomar Baleeiro "introduzido na linguagem financeira da França pelo inventário Schuman e cedo copiado pelo Brasil," a parafiscalidade "traduz a delegação, pela pessoa política, por meio de lei, de sua capacidade tributária ativa, vale dizer, das aptidões de arrecadar e descalizar a exigência de tributos a outra pessoa, de direito público ou privado". (BALEEIRO, 1976 p. 38)

Distancia-se, portanto, das funções extrafical e fiscal por relacionar-se à capacidade tributária ativa e não a competência tributária como os primeiros.

Não obstante, Hugo de Brito Machado aproxima os conceitos ao traçar sua distinção em razão dos objetivos aspirados. Segundo o autor, enquanto o objetivo da função fiscal é a arrecadação de recursos financeiros para o Estado e da função extrafiscal a interferência deste no domínio econômico, a função parafiscal almeja a arrecadação de recursos para o custeio de atividades não exclusivas do Estado, mas que este desenvolve por meio de entidades específicas. (MACHADO, 2010 p. 74)

Feita essas considerações acerca da parafiscalidade, é mister tecer comentários acerca das demais funções elencadas, sem olvidar-se, contudo, que a classificação ocorre diante da função preponderante do tributo, de maneira que a existência de uma não implica na abstenção da outra função, em outras palavras, a fiscalidade e a extrafiscalidade coexistem em todos os tributos.

Sobre o tema o professor Paulo de Barros Carvalho elucida:

Fala-se em fiscalidade sempre que as organizações jurídicas do tributo denuncie que os objetivos que presidiram sua instituição, ou que governam certos aspectos da sua estrutura, estejam voltados ao fim exclusivo de abastecer os cofres públicos, sem que outros interesses- sociais, políticos ou econômicos- interfiram no direcionamento da atividade impositiva. (CARVALHO, 2005 p. 234)

Tradicionalmente as imposições tributárias são percebidas dessa maneira, como financiadoras da atividade estatal, provendo os recursos monetários necessários para o desempenho de seus deveres, ou seja, fiscal.

Não é diferente o conceito da ministra do STJ Regina Helena Costa, para quem a fiscalidade "significa olhar para o tributo, simplesmente, como ferramenta de arrecadação, meio de geração de receita. É a noção mais recorrente quando se pensa em tributação.” (COSTA, 2009 p. 48).

É evidente que todo tributo visa a arrecadação pecuniária, todavia, como explanado, a ela não se limita. Nesse diapasão, emerge a extrafiscalidade, como eficiente arma de intervenção estatal não só na manutenção da economia, mas na promulgação dos interesses sociais. 
A extrafiscalidade, embora reconhecida como moderna técnica de intervenção do Estado na economia, já era verificada na antiguidade. De qualquer modo, sua significância na área econômica é hialina, e sua utilização como instrumento de promulgação dos direitos constitucionais se faz imperiosa.

Note-se que Regina Helena Costa definiu-a como sendo "o emprego de instrumentos tributários para o atingimento de finalidades, não arrecada tórias, mas sim, incentivadoras ou inibitórias de comportamentos, com vista à realização de outros valores.” (COSTA, 2009 p. 48)

Depreende-se que agora a ideia de tributo ultrapassa os fins monetários, de modo que o Estado infiltra-se no âmbito particular de maneira mais extensa do que simplesmente econômica, repercutindo das ações de seus nacionais.

A comumente citada definição de Roque Antonio Carrazza reproduz de maneira certeira a estratégia adotada, pois "há extrafiscalidade quando o legislador, em nome do interesse coletivo, aumenta ou diminui as alíquotas e/ou as bases de cálculo dos tributos, com o objetivo principal de induzir os contribuintes a fazer ou a deixar de fazer alguma coisa". (CARRAZZA, 2011 p. 118)

Destarte, o Estado utiliza-se de mecanismos tributários a fim de moldar as ações particulares e promover os direitos basilares sociais previstos da Carta Republicana.

Em sentido complementar ao exposto sobre a ingerência na conduta singular através da atividade tributária, Aliomar Baleeiro arremata lecionando que toda e qualquer medida nesse sentido deve ser estudada e analisada previamente, levando-se em conta bases racionais e factíveis, bem como seus efeitos em dadas circunstancias. (BALEEIRO, 1976 p. 191)

Em outros termos, o doutrinador alerta que a intervenção estatal não é indiscriminada, mas sim direcionada a um fim especifico, que em última instância deve ser salvaguardado por previsão constitucional, e sem perder de vista todos os seus possíveis reflexos na sociedade.

Em suma, a Constituição Federal contempla grande número de valores e objetivos a serem alcançados na busca pelo Estado Eficiente, sendo que neste ínterim o ordenamento jurídico conciliado com as conjecturas doutrinárias deu forma a extrafiscalidade tributária como ferramenta para aquele fim.

Embora emoldurando as atitudes dos particulares através de mecanismos fiscais, não se pode olvidar que extrafiscalidade, assim como a fiscalidade e a parafiscalidade, trata-se de um instituto tributário e, desta feita, deve obediência a toda estrutura legal que regulamenta o sistema tributário pátrio, não podendo ultrapassar tais rédeas, ainda que na perspectiva de incrementar os pilares constitucionais. 


\section{2: Manejo da Extrafiscalidade em prol do Meio Ambiente}

Com o nascimento da preocupação ambiental nasceram também estratégias para promulgar sua preservação.

Assim, a ideia de tributação ambiental, no âmbito pátrio, tem seu cerne na Constituição de 1988, pois, em seus termos, depreende-se a necessidade de compatibilização do direito tributário, econômico e ambiental.

Em sua tese de conclusão do mestrado Thais Bernardes Maganhini traduz de maneira cirúrgica o ideal dos tributos ambientais, senão, vejamos:

Os tributos ambientais não são "sanções", pois não poderão ter como hipótese de incidência tributária ato ilícito, conforme dispõe o art. $3^{\circ}$ do CTN, mas têm sua importância ímpar na preservação do meio ambiente, através de instrumento de Intervenção do Estado, como incentivador de comportamentos positivos na proteção do meio ambiente e de direcionar as atividades estatais para o implemento de políticas públicas relacionadas como desenvolvimento econômico e o meio ambiente. (MAGANHINI, 2007 p. 79)

Percebe-se, portanto, que a intervenção tributária na esfera ambiental distancia-se da política tradicional brasileira em busca do meio ambiente ecologicamente equilibrado proferido pela Constituição, pois, diferentemente do ideal sancionatório e restaurador, a tributação ambiental atua de maneira prévia e direcionadora.

Não discorda Melissa Guimarães Castello que, em seu texto afirma que esses tributos têm como

Principal objetivo desestimular a produção e o consumo de bens danosos ao meio ambiente. Eles são cada vez mais valorizados como uma alternativa interessante às políticas de repressão, que ainda predominam na proteção ao meio ambiente. (CASTELLO)

A dicotomia dessas ferramentas estatais é evidente, apesar da coincidente finalidade. Não obstante, em que pese a segmentação temporal de suas atividades, o Estado deve utilizar-se de todas as suas estruturas na busca do meio ambiente ecologicamente equilibrado.

Acrescenta ainda Paulo Henrique do Amaral que

O desenvolvimento sustentável não se pratica apenas com a monetarização dos recursos ambientais ou com sua compensação econômica, mas pela execução de projetos e políticas efetivas de prevenção de eventuais danos ao meio ambiente, redução e recuperação daquilo que já foi degradado. É dentro desse contexto que 
se deve desenvolver qualquer espécie de política de proteção ambiental, para isso se deve observar os princípios de direito ambiental, como o da precação, prevenção, cooperação e poluidor pagador. ( $\mathrm{O}$ tributo como instrumento de tutela do meio ambiente, 2009 p. 226)

Logo, a criação de medidas deve também transpor os princípios ambientais, cuja presença é basilar em todo ordenamento que esteja voltado para a promoção do preceituado no art. 225 da Constituição.

Aqui se deve tocar na conclusão de Celso Antonio Pacheco Fiorillo, para quem, tais posicionamentos governamentais não ocorrem apenas para a promoção de um meio ambiente ecologicamente equilibrado, mas sim, como todas as normas republicanas, tem sua gênese na dignidade da pessoa humana. (FIORILLO, 2009 p. 609)

O doutrinador traz sempre em seu pensamento o fim último que toda e qualquer norma se destina, o qual não se nega, contudo, se afasta na tentativa de evitar desvios.

Verifica-se, portanto, conforme doutrina de Renata Marques Ferreira e Celso Antonio Pacheco Fiorillo, que a atividade pública destinada à tributação ambiental também

Revela balizas rígidas e diversas limitações, representadas pela necessária observância dos princípios constitucionais tributários tais como: isonomia, capacidade contributiva, legalidade ou estrita legalidade, irretroatividade, anterioridade, proibição de confisco, e outros princípios encontrados na Carta Magna. (FERREIRA, et al., 2005 p. 42)

Fica evidente que se trata de uma intersecção do direito, em que normas e princípios de ambos os lados devem ser respeitados na produção da atividade tributária ambiental, tendo sempre como objetivo a mecanização do tributo em prol do ambiente saudável.

Assim sendo, independentemente da função predominante o resultado nas condutas humanas será evidente, devendo, portanto, a política tributária ambiental ser desenvolta a luz dos princípios ambientais e tributários, para a promulgação dos seus fins, mas destacando-se sua influencia extrafiscal como diferencial.

Como explanado a pouco, a extrafiscalidade sobrepõe-se dentro da temática da tributação ambiental como ferramenta estatal na efetivação dos deveres constitucionais em tela.

Sua notoriedade na questão ambiental decorre não só em razão dos seus fins extra pecúnia, mas também em razão do tradicional caráter fiscal estar mais próximo do âmbito administrativo do que tributário. 
Ora, não se nega a relevância das questões administrativas, mas quando se recorre ao sistema tributário na promoção do meio ambiente deve-se superar o ideal arrecadatório, pois a este extrapola o direcionamento dos fundos percebidos.

Superada a questão, as palavras de Renato Bernardi acerca da extrafiscalidade envolvendo a temática merecem destaque:

Por meio da extrafiscalidade tributária, tendo como instrumento os benefícios fiscais, pretende-se alterar comportamentos humanos por intermédio da exação tributária. Porquanto, valendo-se dos incentivos fiscais, pode-se desestimular comportamentos nocivos ao meio ambiente, os quais podem ser mudados não através da utilização de novos tributos a serem aplicados aos comportamentos causadores da degradação, mas sim utilizando-se da "sanção premial", para aqueles setores que mudarem suas atitudes, implementando novas tecnologias, com o objetivo de ir ao encontro do desenvolvimento sustentável, que somente poderá ser alcançado com uma política pública que fomente e incentive os setores produtivos, premiando aqueles que contribuem na trilha deste caminho e punindo os que teimam em praticar atividades que venham a degradar o meio ambiente em níveis insuportáveis. (BERNARDI)

Indubitavelmente, a questão não se limita ao sistema tributário, mas prescinde de uma administração pública estruturada. Contudo, a extrafiscalidade tem se demonstrado como alternativa válida e eficaz na modernização da política ambiental, atuando no direcionamento humano.

Neste ínterim, Melissa Guimarães Castello eleva a cumulação dos princípios ambientais do poluidor pagador e da prevenção como pilastra desta atuação extrafiscal, afinal, com aquele se internaliza o valor do dano ambiental ao custo do produto e através deste a "produção ou o consumo dos bens prejudiciais ao meio ambiente tendem a diminuir na medida em que esses bens se tornam mais caros, devido à incidência tributária". (CASTELLO)

Evidentemente, não se nega, tampouco exclui outras medidas, sejam elas de caráter civil, administrativo, econômico ou mesmo penal, afinal, apenas com a utilização orquestrada de todo este aparato o Estado atingirá seus desígnios.

O que se preza aqui, todavia, é a utilidade do âmbito tributário em prol do meio ambiente saudável e, nesse contexto, Thais Bernardes Maganhini conclui que

A extrafiscalidade é o maior instrumento de indução para a busca do desenvolvimento sustentável, pois incide sobre a produção e o consumo, por meio de mecanismos de graduação de alíquotas, reduções de base de calculo e seletividade, isenções e restrições, dependendo da natureza dos produtos, visando aumentar ou desestimular a produção de produtos nocivos ao meio ambiente, 
ou aqueles que o processo de produção afete negativamente o meio ambiente. (MAGANHINI, 2007 p. 86)

Em síntese, é através de uma política fiscal bem estruturada que se tende a evitar o dano ambiental.

Ademais, o Brasil é amplamente conhecido por sua alta carga tributária, o que implica na possibilidade de rejeição a instituição de qualquer novo tributo, de maneira que o resultado negativo ainda pode resvalar em outro setor nacional.

Destarte, deve o Estado estar atento as minúcias que permeiam a temática e, dar preferência a utilização dos instrumentos já existentes, em especial a extrafiscalidade.

\section{TRIBUTOS E O ESTATUTO DA CIDADE}

\subsection{Os instrumentos tributários no Estatuto da Cidade}

Com o advento da Constituição Cidadã as percepções acerca dos pilares governamentais mudaram e novos objetivos tomaram frente no Estado brasileiro, na tentativa de satisfazer os anseios sociais dos séculos XX e XXI. Nesse diapasão a dignidade da pessoa humana tornou-se um dos fundamentos da República, e, desta feita, parâmetro interpretativo dos demais direitos.

Deste modo, o direito à propriedade passou a ser reinterpretado sob a ótica coletiva, e a necessidade de cuidados na consecução do direito ao meio ambiente equilibrado tomou força.

Ainda neste mesmo contexto histórico, observamos que a cidade passou a ter protagonismo, na medida em que se tornou centro econômico e populacional do Estado, além de ser ela quem conjuga efetivamente os supracitados direitos à propriedade e ao meio ambiente.

Sobre o tema destacamos a ideia de Celso Antônio Pacheco Fiorillo, para quem a partir de 1988 a cidade passa a ser disciplinada em face da estrutura jurídica do bem ambiental e como tal encontra proteção mediata na ideia geral de meio ambiente (art. 225 da CF) e imediata, enquanto meio ambiente artificial, cuja proteção emanada dos arts. 182 e 183 da Carta Magna. (FIORILLO, 2013 p. 646)

O caráter programático destas normas constitucionais devolve ao Estado a necessidade de atuação na promulgação das cidades, agora não apenas como centro econômico, mas também ambiental e, porque não, social. Logo, cabe a ele desenvolver uma política urbana adequada, capaz de instituir diretrizes para o desenvolvimento da urbe, inclusive no campo da habitação.

Aquele mesmo autor então complementa: "a Constituição Federal de 1988 fixa como objetivos da política urbana: a) a realização do pleno desenvolvimento das funções sociais da cidade; e b) a garantia de bem estar dos seus habitantes." (FIORILLO, 2013 p. 636)

Assim, foi do alinhamento destes pensamentos que o Estado passou a tomar frente na 
realização destes desígnios, dando origem a lei 10.257, mais conhecida como Estatuto da Cidade.

Para José Afonso da Silva é no incremento da pólis que se encontram

(...) os fundamentos constitucionais do Estatuto da Cidade, instituído pela Lei $10.257 / 2001$, que estabelece as diretrizes gerais de politica urbana, segundo o previsto nos arts. 21, XXI, 182 e 183 da CF. O Estatuto da Cidade, denominação conferida àquela lei pelo parágrafo único de seu art. $1^{\circ}$, estabelece as diretrizes gerais da política urbana, que tem por objetivo ordenar o pleno desenvolvimento das funções sociais da cidade e da propriedade urbana em prol do bem coletivo, da segurança e do bem-estar dos cidadãos, bem como o equilíbrio ambiental. (SILVA, 2012 p. 58)

Ora, o Estatuto da Cidade nada mais é do que um passo a frente na concretização da política urbana dado pela União, sem, contudo usurpar qualquer competência que lhe é estranha.

Nesse sentido, o doutrinador José Afonso da Silva afirma que essa norma federal, em verdade, assume o papel de lei nacional, com características de uma lei geral de direito urbanístico, pois institui princípios, disciplina diversas figuras e institutos do direito urbanístico, "fornece um instrumental a ser utilizado na ordenação dos espaços urbanos, com observância da proteção ambiental, e a busca de solução para problemas sociais graves”. (SILVA, 2012 p. 67)

Outra não poderia ser a conclusão, afinal, a busca pelo meio ambiente equilibrado, embora seja de competência comum (art. 23, VI da CF), por sua característica ímpar, exige que seja galgada pelo Estado enquanto nação (art. 23, parágrafo único $\mathrm{CF}$ ).

Isto posto, Jorge Henrique de Oliveira Souza, nos rememora que o Estatuto da Cidade estabelece diretrizes de "como, quando e onde edificar de maneira a atender os interesses sociais, combatendo a especulação imobiliária e fazendo com que a propriedade imobiliária cumpra sua função social". (SOUZA, 2009 p. 297)

Ou seja, ele traz a baila a função social da cidade e, consequentemente da propriedade, como questão importante a ser ponderada na execução do Estatuto da Cidade, juntamente com o conteúdo ambiental.

A importância da função social da cidade merece o reforço das palavras de Celso Antônio Pacheco Fiorillo, senão vejamos:

Isso significa dizer que a função social da cidade é cumprida quando esta proporciona a seus habitantes o direito à vida, à segurança, à igualdade, à propriedade e à liberdade $\left(\mathrm{CF}\right.$, art. $5^{\circ}$ caput), bem como garante a todos um piso vital mínimo, compreendido pelos direitos sociais à educação, à saúde, ao lazer, ao trabalho, à previdência social, à maternidade, à infância, à assistência aos desamparados, entre outros encartados no art. $6^{\circ}$. (FIORILLO, 2013 p. 637)

Destarte o cumprimento da função social da cidade proporciona a seus habitantes o exercício de inúmeros outros direitos, fato que, portanto, demonstra a magnitude da temática. Logo, questionam-se quais seriam as ferramentas que o Estado dispõe para tal fim. 
Para Toshio Mukai a resposta está dentro do próprio direito urbanístico, que, no Brasil, faz uso das limitações administrativas (urbanísticas), das desapropriações e dos tributos regulatórios como instrumentos jurídicos. (MUKAI, 2002 p. 67)

Acerca dos tributos utilizados na ordenação da cidade e veiculados no Estatuto da Cidade, tema do presente trabalho, temos o imposto predial e territorial urbano e a contribuição de melhoria ambiental, estudados individualmente a seguir.

\subsection{O imposto sobre a propriedade predial e territorial urbana- IPTU}

Imposto é, em resumo, a prestação pecuniária paga em prol do Estado, quando da ocorrência da prevista hipótese de incidência, sem que isso necessite de uma contraprestação específica (art. 16 do $\mathrm{CTN}^{3}$ ). "Portanto, basta que o sujeito passivo realize qualquer das situações previstas em lei para que a pessoa política competente esteja autorizada a exigir o imposto correspondente", como finaliza Regina Helena Costa. (COSTA, 2009 p. 110)

A Constituição Cidadã instituiu algumas hipóteses de incidência, sobre as quais delimitou as competências entre os entes federativos. Assim, ficou sob a égide dos Municípios a regulamentação dos impostos sobre a propriedade predial e territorial urbana (art. 156, I da $\mathrm{CF}^{4}$ ).

Tal tributo tem "como fatos geradores a propriedade, o domínio útil ou a posse de bem imóvel por natureza ou por acessão física, como definido na lei civil, localizado na zona urbana no Município", de acordo com o que condensa Leandro Paulsen. (PAULSEN, 2012 p. 347)

Embora a função fiscal do discutido tributo seja preponderante, até mesmo por ser este, via de regra, a maior fonte de renda municipal, a análise da função extrafiscal do IPTU é primordial, haja vista a repercussão do mesmo na organização dos espaços urbanos.

Tal conclusão segue paralela ao pensamento de Toshio Mukai que assevera a constitucionalidade do uso extrafiscal e regulatório do IPTU e enfatiza o imposto como um dos que mais se prestam a regular os problemas urbanísticos. (MUKAI, 2002 p. 84)

E foi mediante tal importância que o Estatuto da Cidade trouxe de maneira expressa o Imposto sobre a propriedade predial e territorial urbana - IPTU como um de seus institutos tributários e financeiros.

Não discorda Jorge Henrique de Oliveira Souza quando diz que da análise justaposta entre o Estatuto e a Constituição, o IPTU pode ser utilizado "como instrumento de ordenação do espaço urbano, ou seja, com nítido caráter extrafiscal (finalidade urbanística), o que passa, necessariamente, pela análise da progressividade das alíquotas na sua instituição". (SOUZA, 2009 p. 301)

Desta maneira, a progressividade ganha relevo, afinal é ela quem garante o exercício da extrafiscalidade. Através da modulação de alíquotas se consegue adequar o preenchimento dos

3 Art. 16. Imposto é o tributo cuja obrigação tem por fato gerador uma situação independente de qualquer atividade estatal específica, relativa ao contribuinte.

4 Art. 156. Compete aos Municípios instituir impostos sobre:

I - propriedade predial e territorial urbana; 
espaços urbanos com as pretensões estatais.

De maneira assertiva Adilson Abreu Dallari discorre sobre a matéria, senão vejamos:

Quanto ao IPTU, a fixação de sua alíquota sempre repercutirá significativamente no montante da arrecadação tributária e sempre, também, será um instrumento de política tributária ligada ao desenvolvimento urbano, pois sempre servirá como instrumento de promoção do adequado nível de ocupação do solo e adensamento populacional.

A Constituição Federal cuida de atribuir ao IPTU uma considerável flexibilidade no tocante à fixação do valor a ser cobrado do contribuinte, exatamente para viabilizar sua utilização como instrumento de urbanismo. Em seu art. 182, §4 $4^{\circ}$, II, ela menciona o IPTU progressivo no tempo, como instrumento de promoção do adequado aproveitamento do imóvel urbano não edificado, subutilizado ou não utilizado. Além dessa específica forma de progressividade, no art. $156, \S 1^{\circ}$, I, está previsto, também, que esse imposto pode ser progressivo em razão do valor do imóvel. Esta ultima forma de progressividade já foi objeto de controvérsia, que acabou sendo eliminada com a promulgação da Emenda Constitucional 30, de 13.9.2000, que afirmou de maneira inequívoca a sua viabilidade. Nesse mesmo parágrafo desse mesmo artigo, mas no inciso II, está prevista expressamente a possibilidade de fixação de alíquotas diferentes, de acordo com a localização do imóvel. Tudo isso efetivamente confere ao IPTU um formidável poder de fogo como instrumento de política de realização das finalidades e objetivos do urbanismo e da justiça social, nos termos do art. $3^{\circ}$, III da Constituição Federal. (Instrumentos da Política Urbana, 2003 p. 79)

O IPTU, portanto, é capaz de incentivar a ocupação de determinados espaços do Município através da inserção de alíquotas mais baixas, do mesmo modo que inibe outros por meio da elevação, nos moldes da aquiescência constitucional, qual seja, fundamentados na localização e no uso do bem.

Ao abordar o tema Leandro Paulsen divide a progressividade de acordo com o artigo constitucional que a autoriza, art. $156, \S 1^{\circ}$ ou art. 182. Assim, o autor comenta os dispositivos que tratam da progressividade do imposto em relação ao valor do imóvel, este somado a seletividade cominada à localização e ao uso do bem, e, juntamente com outras ferramentas de política urbana como o parcelamento compulsório e a desapropriação, a progressividade no tempo. Acerca desta última o autor conclui ser ela a "razão pela qual os proprietários de terrenos urbanos pagam mais IPTU que os proprietários de casas, embora o valor venal dessas com seus terrenos seja muito superior ao daqueles". (PAULSEN, 2012 p. 346)

Deste modo, a tese do doutrinador perfila-se a ideia de que as alíquotas forçam os cidadãos a darem a destinação social necessária as suas propriedades, afinal, se assim não o fosse a cidade ficaria a mercê das especulações imobiliárias e jamais seria capaz de cumprir sua função social.

E complementando esse pensamento Cintia Estefania Fernandes expõe que

O Estatuto da Cidade viabiliza a implementação do IPTU progressivo no tempo, 
que não terá fim arrecadatório, sendo um instrumento para que os proprietários promovam o adequado aproveitamento do imóvel, ou seja, um meio de dar à propriedade, função social, anterior à desapropriação com fins urbanísticos. (FERNANDES, 2005 p. 397)

É dever do Poder Público conduzir a ocupação dos espaços urbanos, nos termos da Carta Magna e do Estatuto da Cidade, direcionando a conduta de seus habitantes. O objetivo é garantir a todos o acesso à cidade, fato que não se opõe ao exercício do direito de propriedade.

Diante de tal finalidade, torna-se imprescindível a existência do Plano Diretor, instrumento de planejamento expressamente previsto naqueles mesmos regramentos, para a melhor execução da política urbana e garantia de que esta não seja corrompida por interesses particulares.

Por fim, é mister ressaltar que a extrafiscalidade prescrita deve ter como norte o cumprimento da função social da propriedade e, como fim ultimo, a obtenção do meio ambiente urbano equilibrado.

\subsection{Contribuição de melhoria}

A contribuição de melhoria é, segundo a teoria pentapartite, uma espécie tributária autônoma prevista no art. $5^{\circ}$ do CTN e didaticamente conceituado pelo art. $81^{5}$ do mesmo diploma como tributo instituído em face ao custo de obras públicas de que decorra valorização imobiliária.

Essa contribuição sedimenta-se não apenas como fonte de receita, mas também como forma de elidir o locupletamento ilícito daqueles que se beneficiaram da obra pública. Trata-se de verdadeira justiça social, pois impede que um grupo seja beneficiado de modo superior aos demais e à custa da coletividade.

Em apertada síntese Leandro Paulsen transmite esse mesmo pensamento ao afirmar que "efetivamente, havendo benefício direto para algumas pessoas, é razoável que o seu custeio não se dê por toda sociedade igualmente, mas especialmente, por aqueles a quem a obra aproveite". (PAULSEN, 2012 p. 39)

A contribuição de melhoria também tem previsão constitucional (art. 145, III). Ora, diante da importância desse instrumento tributário no exercício da justiça distributiva e, por conseguinte, ser ele um dos mais fáceis tradutores dos objetivos constitucionais, a Carta Magna não poderia deixar de prevê-lo em seu texto e, desta feita, salvaguarda-lo na mais alta norma pátria.

Sem dúvida a função extrafiscal desse tributo merece ênfase, principalmente diante de seus efeitos perante a urbe. A contribuição de melhoria demonstra uma "perfeita adequação a uma das principais diretrizes gerais de política urbana, afirmada pelo art. $2^{\circ}$, IX, do Estatuto da Cidade, qual seja: a justa distribuição dos benefícios decorrentes do processo de urbanização", conforme preleciona Adilson Abreu Dallari. (Instrumentos da Política Urbana, 2003 p. 79)

5 Art. 81. A contribuição de melhoria cobrada pela União, pelos Estados, pelo Distrito Federal ou pelos Municípios, no âmbito de suas respectivas atribuições, é instituída para fazer face ao custo de obras públicas de que decorra valorização imobiliária, tendo como limite total a despesa realizada e como limite individual o acréscimo de valor que da obra resultar para cada imóvel beneficiado. 
Assim, a utilização do efeito extrafiscal deste tributo na organização das cidades torna essa ferramenta jurídica um dos meios de se otimizar o ordenamento pátrio. Em outros termos, trata-se de uma solução para a política urbana através do uso de ferramentas já disponíveis ao Estado e, posto isso, deve ter sua prática estimulada.

No mesmo norte, Regina Helena Costa aduz que

Com a edição do Estatuto da Cidade pretende o legislador incentivar a instituição dessa espécie tributária, pois aponta, como lembrado, a recuperação dos investimentos do Poder Público de que tenha resultado a valorização de imóveis urbanos como diretriz geral da política urbana (art. 2, IX). É o princípio da afetação das mais-valias ao custo da ubarnificação operando seus efeitos.

Sendo meio de captação de recursos de proprietários particulares cujo patrimônio valorizou-se em decorrência de investimentos públicos, propicia que parte dessa riqueza retorne aos cofres públicos, em benefício da coletividade. (Instrumentos Tributários para a Implementação da Política Urbana, 2003 p. 114)

Impende salientar que a promoção do uso da contribuição de melhoria no âmbito da política urbana não se resumiu a convergência dos fins entre ambos. O legislador fez questão de prever expressamente a utilização daquela na consecução dos fins urbanísticos. (art. $4^{\circ}, \mathrm{IV}, \mathrm{b}$ do Estatuto da Cidade $^{6}$ ), dando ainda mais ênfase neste mecanismo.

Não obstante, Jorge Henrique de Oliveira Souza nos adverte que a contribuição de melhoria, mesmo quando vertida para fins ambientais, como é o caso, deve ser cobrada apenas após o término da obra e que enseje a valorização imobiliária, ou seja, não se trata de um instrumento de formação de capital. (SOUZA, 2009 p. 325)

Afirmação essa que reforça a importância extrafiscal do tributo em voga, isto é, a visão da contribuição de melhoria não como meio arrecadatório, regra entre os tributos, mas sim como verdadeiro instrumento de justiça social capaz ainda de atender a preservação e proteção do meio ambiente artificial, conforme fundamentos constitucionais e infraconstitucionais.

\section{CONSIDERAÇÕES FINAIS}

É sabido que as cidades passaram a ter um papel dirigente na estrutura da sociedade, haja vista que os espaços urbanos tornaram-se os cérebros econômicos e centros sociais do Estado. Desta feita, a organização desses espaços deve fazer parte dos planos governamentais.

Destarte, instituíram-se ferramentas para que os entes políticos possam galgar o meio ambiente urbano equilibrado consubstanciado com a aplicação da função social da propriedade.

É o caso do Imposto Predial e Territorial Urbano e da Contribuição de Melhoria, instrumentos tributários explanados pelo Estatuto da Cidade com o aval constitucional, como

6 Art. 4o Para os fins desta Lei, serão utilizados, entre outros instrumentos:

IV - institutos tributários e financeiros:

b) contribuição de melhoria; 
ferramentas já existentes no ordenamento, mas que devem ter sua função extrafiscal destacada na finalidade de ascensão de uma política urbana adequada.

Embora seja de destaque a necessidade de incentivo a estes instrumentos, afinal, fazer uso de ferramentas que já existem em prol mais de uma finalidade é maximizar o ordenamento, seu exercício nos moldes gerais não é o suficiente.

O plano diretor, norma de competência Municipal, é imprescindível para a devida abordagem desses tributos como medida de política urbana, pois ambos exigem a lei municipal para uma melhor execução.

Em suma, a cidade deve ser observada como preocupação universal, abordando os cidadãos e o Estado em todas as suas esferas, aquele suportando as intervenções deste em sua propriedade e este último tomando uma posição ativa na obtenção do meio ambiente urbano equilibrado.

\section{REFERÊNCIAS BIBLIOGRÁFICAS}

ARAÚJO, Cláudia Rezende Machado de. Extrafiscalidade. Revista de Informação Legislativa, $n^{\circ}$ 132. [Online] Outubro/Dezembro de 1996. http://www.senado.gov.br/web/cegraf/ril/Pdf/ pdf_133/r133-29.PDF. Visitado em: 21 de Agosto de 2013

BALEEIRO, Aliomar. Uma introdução à ciência das finanças. $11^{\circ}$ edição. Rio de Janeiro : Forense, 1976.

BERNARDI, Renato. Tributação Ecológica (o uso ambiental da extrafiscalidade e da seletividade tributárias). [Online] http://www.professorsabbag.com.br/arquivos/downloads/1277138171.pdf. Visitado em: 18 de Junho de 2015

BRANCO, Paulo Gustavo Gonet e MENDES, Gilmar Ferreira. Curso de Direito Constitucional. [Livro Digital] $7^{\circ}$ edição. São Paulo : Saraiva, 2012.

BRASIL. Constituição (1988). Constituição da República Federativa do Brasil: promulgada em 5 de outubro de 1988. Disponível em: < http://www.planalto.gov.br/ ccivil_03/constituicao/constituicao.htm>. Visitado em: 10 de junho de 2015 .

. Lei 5.172 de 25 de outubro de 1966. Dispõe sobre o Sistema Tributário Nacional e institui normas gerais de direito tributário aplicáveis à União, Estados e Municípios. [Online] Disponível em: < http://www.planalto.gov.br/ccivil_03/Leis/L5172.htm>. Visitado em: $10 \mathrm{de}$ junho de 2015

. Lei 10.257, de 10 de julho de 2001. Regulamenta os arts. 182 e 183 da Constituição Federal, estabelece diretrizes gerais da política urbana e dá outras providências. Disponível em: < http://www.planalto.gov.br/ccivil_03/leis/LEIS_2001/L10257.htm>. Visitado em: $10 \mathrm{de}$ junho de 2015

CARRAZZA, Roque Antonio. Curso de direito constitucional tributário. $27^{\circ}$ edição. São Paulo : Malheiros, 2011. 
CARVALHO FILHO, José dos Santos. Manual de direito administrativo. $25^{\circ}$ edição. São Paulo : Atlas, 2012.

CARVALHO, Paulo de Barros. Curso de Direito Tributário. $17^{\circ}$ edição. São Paulo : Saraiva, 2005.

CASTELLO, Melissa Guimarães. A possibilidade de instituir tributos ambientais em face da Constituição de 1988. [Online] http://www.egov.ufsc.br/portal/sites/default/files/anexos/2071220713-1-PB.htm. Visitado em: 17 de Junho de 2013

COSTA, Regina Helena. Curso de direito tributário: Constituição e Código Tributário Nacional $.1^{\circ}$ ed. $2^{\circ}$ tir. São Paulo : Saraiva, 2009.

. Instrumentos Tributários para a Implementação da Política Urbana. Estatuto da Cidade-comentários à lei federal 10.257/2001, pp. 107-116. $1^{\circ}$ ed. $2^{\circ}$ tir. São Paulo: Malheiros, 2003.

DALLARI, Adilson Abreu. Instrumentos da Política Urbana. Estatuto da Cidade- comentários à lei federal 10.257/2001, pp. 107-116. $1^{\circ}$ ed. $2^{\circ}$ tir. São Paulo: Malheiros, 2003.

DI PIETRO, Maria Sylvia Zanella. Direito adminitrativo. $27^{\circ}$ edição. São Paulo : Atlas, 2014. FARIAS, Cristiano Chaves de e ROSENVALD, Nelson. Curso de Direito Civil, Direitos Reaisv5. $2^{\circ}$ edição. Salvador : JusPodivm, 2012.

FERNANDES, Cintia Estefania. IPTU- Texto e Contexto. São Paulo : Quartier Latin, 2005.

FERREIRA, Renata Marques e FIORILLO, Celso Antonio Pacheco. Direito Ambiental Tributário. São Paulo : Saraiva, 2005.

FIORILLO, Celso Antonio Pacheco. Curso de Direito Ambiental Brasileiro. $10^{\circ}$ edição. São Paulo : Saraiva, 2009.

2013.

. Curso de direito ambiental brasileito. [Livro Digital] $14^{\circ}$ edição. São Paulo : Saraiva,

GONÇALVES, Carlos Roberto. Direito civil brasileiro v.5. [Livro Digital] $7^{\circ}$ edição. São Paulo : Saraiva, 2012.

MACHADO, Hugo de Brito. Curso de Direito Tributário. $31^{\circ}$ edição. São Paulo : Malheiros, 2010.

MAGANHINI, Thais Bernardes. Extrafiscalidade Ambiental: um instrumento de compatibilização entre o desenvolvimento econômico e meio ambiente. Marilia : Tese (Mestrado em Direito)- Curso de Pós Graduação em Direito, Universidade de Marilia, 2007.

MUKAI, Toshio. Direito Urbano-Ambiental Brasileiro. São Paulo : Dialética, 2002. O tributo como instrumento de tutela do meio ambiente. CARVALHO, Valbério Nobre de e RIBAS, Lidia Maria ${ }^{\circ}$ 54, São Paulo : Revista dos Tribunais, ano 14, Abril/Junho de 2009, Revista de Direito Ambiental, p. 226.

PAULSEN, Leandro. Curso de direito tributário: completo. [Livro Digital] $4^{\circ}$ edição Porto 
Alegre : Livraria do Advogado, 2012.

. Impostos federais, estaduais e municipais. [Livro Digital] $14^{\circ}$ edição Porto Alegre :

Livraria do Advogado, 2012.

SILVA, José Afonso da. Curso de direito constitucional positivo. São Paulo : Malheiros, 1999. . Direito Urbanístico Brasileiro. São Paulo : Malheiros, 2012.

SOUZA, Jorge Henrique de Oliveira. Tribitação e meio ambiente . Belo Horizonte : Del Rey, 2009.

TARTUCE, Flávio. Manual de direito civil: volume único. [Livro Digital] $4^{\circ}$ edição. Rio de Janeiro : Método, 2014.

Recebido em:11/05/2020

Aprovado em :01/06/2020 